\title{
Slow light in semiconductor waveguides: Theory and experiment
}

Mørk, Jesper; Öhman, Filip; Poel, Mike van der; Hansen, Per Lunnemann; Nielsen, Torben Roland; Kær Nielsen, Per; Thyrrestrup Nielsen, H.; Yvind, Kresten

\section{Published in:}

European Conference on Lasers and Electro-Optics, 2007 and the International Quantum Electronics Conference. CLEOE-IQEC 2007.

Link to article, DOI:

10.1109/CLEOE-IQEC.2007.4386121

Publication date:

2007

Document Version

Publisher's PDF, also known as Version of record

Link back to DTU Orbit

Citation (APA):

Mørk, J., Öhman, F., Poel, M. V. D., Hansen, P. L., Nielsen, T. R., Kær Nielsen, P., Thyrrestrup Nielsen, H., \& Yvind, K. (2007). Slow light in semiconductor waveguides: Theory and experiment. In European Conference on Lasers and Electro-Optics, 2007 and the International Quantum Electronics Conference. CLEOE-IQEC 2007. IEEE. https://doi.org/10.1109/CLEOE-IQEC.2007.4386121

\section{General rights}

Copyright and moral rights for the publications made accessible in the public portal are retained by the authors and/or other copyright owners and it is a condition of accessing publications that users recognise and abide by the legal requirements associated with these rights.

- Users may download and print one copy of any publication from the public portal for the purpose of private study or research.

- You may not further distribute the material or use it for any profit-making activity or commercial gain

- You may freely distribute the URL identifying the publication in the public portal 


\title{
Slow light in semiconductor waveguides: Theory and experiment
}

\author{
J. Mørk, F. Öhman, M. van der Poel, Per Lunnemann Hansen, \\ Torben Roland Nielsen, P. Kaer Nielsen, H. Thyrrestrup Nielsen, and K. Yvind \\ COM•DTU, Technical University of Denmark, Ørsteds Plads 343, DK-2800 Kgs. Lyngby, Denmark
}

The spectacular experimental demonstration of slowing light to cyclist speed in an ultra-cold atomic gas has spurred a significant interest in exploring the physics and applications of this phenomenon. Important applications that are foreseen include all-optical buffering, true time delays and filters for microwave photonics, as well as increased material nonlinearities for improved sensor elements. We have pursued the realization of slow light in semiconductor waveguides by using the physical effect of coherent population oscillations (CPO), which was demonstrated in Ruby crystals [1]. By exploiting wave mixing effects mediated by the coherent oscillation of the carrier density in a semiconductor waveguide, one can thus change the group velocity of light propagating in the waveguide. Due to the small, and to some extent controllable, carrier lifetime in semiconductors, this effect can be realized within $\mathrm{GHz}$ bandwidths, which is to be contrasted with the $\mathrm{Hz}$ to $\mathrm{MHz}$ bandwidths found in crystals and cold atomic gasses. Furthermore, one can utilize semiconductor fabrication technology to realize compact and integrated structures that optimize certain performances.

Fig. 1 shows measurement results for a multi-section quantum well waveguide structure [2]. Two sections are reverse biased and act as saturable electro absorbers (EA), which lead to slow-down and absorption of light, whereas two forward-biased sections act as semiconductor optical amplifiers (SOAs) that speed-up and amplify the light. By proper operation of the device, it is possible to control the net delay (or, equivalently, the microwave phase) and amplitude of an intensity modulated signal that passes the waveguide. At the conference we will show the frequency response of the device, which is well suited for realizing a true time-delay, and discuss the physics and limitations of the physical effect exploited. Furthermore, we will show experimental and theoretical results on delaying ultrashort optical pulses, with bandwidths in the THz range, in similar waveguide structures.
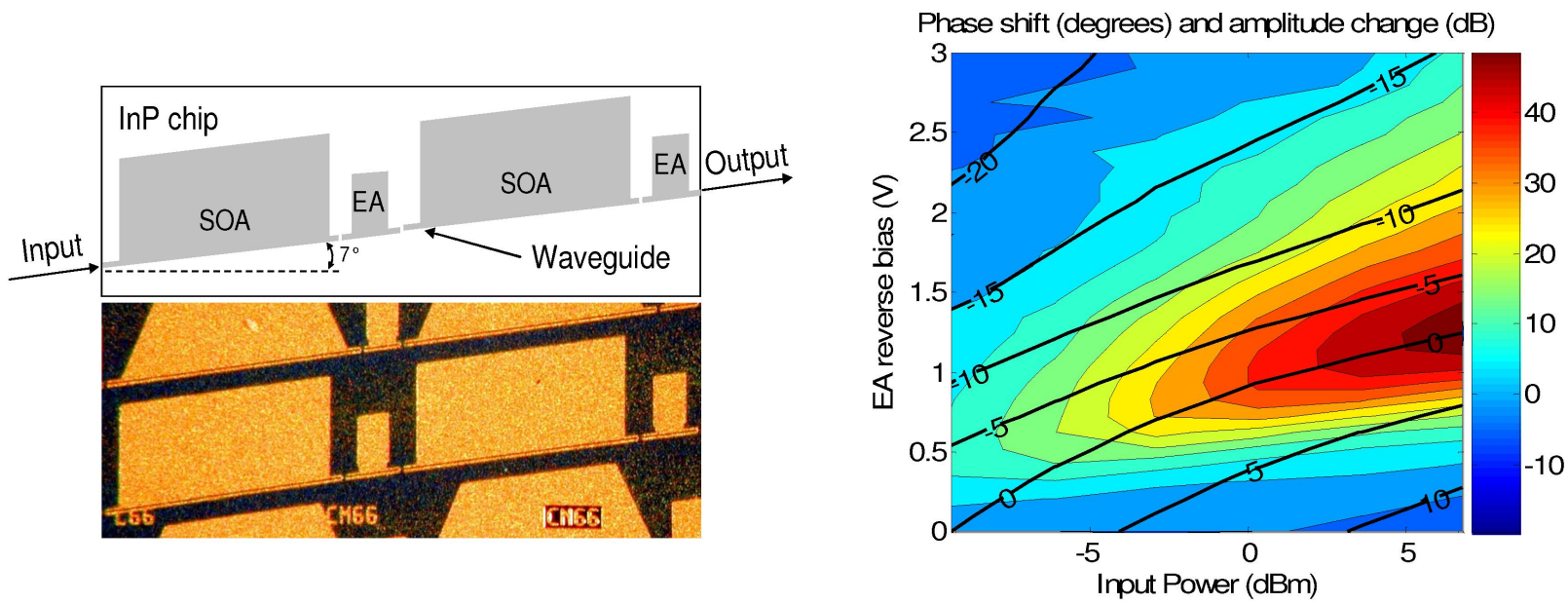

Fig. 1. Schematic diagram and photo of the investigated multi-electrode quantum well waveguide (left) and contour plot of the measured phase shift (right). The measurements are carried out at a modulation frequency of $10 \mathrm{GHz}$ and the contour diagram shows the phase shift (colour code) versus optical input power and reverse bias. Additional contour lines are shown for different levels of net waveguide transmission, ranging from a loss of $-15 \mathrm{~dB}$ to a gain of $10 \mathrm{~dB}$.

Electromagnetically induced transparency (EIT), in contrast to CPO, exploits quantum mechanical interference between electronic state wave functions related to discrete states of the material. So-far this effect has been explored mainly in atomic gasses. However, for practical applications it would be of a significant interest to implement EIT in a compact semiconductor structure, and with their discrete state structure semiconductor quantum dots appear as a natural choice. We will present numerical simulations of the propagation of optical pulses in the regime of EIT in quantum dots, emphasizing the role of dephasing processes and bandwidth limiting effects, which may lead to severe pulse distortions. The main properties of CPO and EIT based slow-light schemes will be compared and discussed.

\section{References}

1. M. Bigelow et al. "Observation of ultraslow light propagation in a ruby crystal at room temperature", Phys. Rev. Lett. 90, 113903-1-4 (2003).

2. F. Öhman, K. Yvind and J. Mørk, "Voltage-controlled slow light in an integrated semiconductor structure with net gain”, Optics Express 14, 9955-9962 (2006). 